\title{
Effect of pH and inoculum size on pentachlorophenol degradation by Pseudomonas sp.
}

\author{
Erika Alejandra Wolski*, Silvia Elena Murialdo and Jorge Froilán Gonzalez \\ Facultad de Ingeniería. Universidad Nacional de Mar del Plata. Juan B Justo 4302-B7608FDQ. Mar del Plata. Argentina
}

\begin{abstract}
Pentachlorophenol (PCP) is a toxic compound which is used as a fungicide, bactericide, herbicide and chemical intermediate. Because of its toxicity, there is a need to decontaminate the PCP-laden soils and bioremediation is a very useful alternative to conventional clean-up methods. The success of this depends on finding strains able to degrade PCP in a changeable environment.

The aim of this work was to study the influence of $\mathrm{pH}$ of the medium and the effect of inoculum size on pentachlorophenol degradation by Pseudomonas sp. A study of PCP degradation kinetics was performed to assess such effects.

PCP was degraded rapidly at $\mathrm{pH}$ values from 6.3 to 8 , but the maximum rate of PCP degradation by Pseudomonas sp. was at $\mathrm{pH}$ 6.3. In contrast, the PCP degradation kinetics at $\mathrm{pH} 5.5$ were significantly lower, although PCP was totally depleted. These results show the broad range of $\mathrm{pHs}$ for PCP degradation for this strain.

PCP was degraded at every inoculum size tested and PCP degradation increased with the increasing inoculum size, but cultures inoculated with the lowest inoculum showed the highest specific consumption rate. This reveals a lower consumption of PCP per CFU at a high population density.

These results are useful to understand the physiological and biochemical properties of Pseudomonas sp. before its optimum use in environmental application and these data will assist in choosing the right PCP-degrader for a changeable environment.
\end{abstract}

Keywords: biodegradation, bioremediation, inoculum size, pentachlorophenol, $\mathrm{pH}$, Pseudomonas sp.

\section{Introduction}

Pentachlorophenol (PCP) has been used as a wood preservative, insecticide, and herbicide and was introduced into the environment by waste streams of several industrial operations. A large amount of PCP is used by the wood-preserving industry (Hoos, 1978; Cirelli, 1978) and PCP contamination in soil represents a serious problem to the environment that surrounds several wood treatment plants and sawmills (Rao, 1978; Valo et al., 1985). PCP is considered a priority pollutant by various regulatory agencies. This polychlorinated aromatic compound is toxic to numerous aquatic organisms at a concentration of as low as $0.5 \mathrm{mg} \cdot \ell^{-1}$ (Borthwick and Schimmel et al., 1978) and adversely affects flora and fauna (Chu and Kirsch, 1973; Liu et al., 1982). It is also suspected to be a human carcinogen (Mc Allister et al., 1996). Because of its toxicity, there is a need to decontaminate the PCP-laden soils.

Several decontamination techniques are available for the removal of contaminants from water, although not all are efficient enough to destroy the contaminant. The use of micro-organisms for bioremediation of PCP-contaminated sites may prove to be a viable alternative to conventional clean-up methods. Biodegradation is a technique which could potentially degrade these contaminants to innocuous products (mainly $\mathrm{CO}_{2}$ and $\mathrm{H}_{2} \mathrm{O}$; also $\mathrm{Cl}^{-}$in the case of chlorinated phenols). Biological treatment of chlorophenols attracts more attention than physical and chemi-

* To whom all correspondence should be addressed.

욜 +54223 4753030; fax: +54223 4751392;

e-mail: ewolski@mdp.edu.an

Received 18 March 2005; accepted in revised form 9 September 2005. cal methods, because a variety of micro-organisms are known to utilise chlorophenols as their sole carbon or energy source and because the reaction products are $\mathrm{Cl}^{-}$ions, $\mathrm{CO}_{2}$ and biomass. Many species of soil bacteria have been isolated from contaminated soil samples. PCP-degrading bacteria include species of Arthrobacter (Stanlake and Finn, 1982), Flavobacterium (Saber and Crawford, 1985), Pseudomonas (Radehaus and Schmidt, 1992), Rhodococcus (Apajalahti and Salkinoja-Salonen, 1986) and Corynebactrium (Chu and Kirsch, 1972). Although several of them do not degrade PCP completely, others produce toxic metabolites and some do not tolerate changes of physical and chemical environmental factors.

In previous work published (Murialdo et al., 2003) a Pseudomonas sp. strain was isolated from a consortium that degrades PCP. It was shown that glucose and glutamate have positive effects on its population density. This micro-organism could be used very effectively for in situ bioremediation in an environment which is highly contaminated with PCP, other chlorinated phenols and hexadecane (Murialdo et al., 2003).

The success of bioremediation may depend on the availability of microbial strains that can mineralise high levels of PCP and withstand adverse conditions to compete under in situ conditions. An effective bacterial inoculum should be able to tolerate high levels of PCP while maintaining a level of activity to provide efficient mineralisation (Shaw et al., 1997). Understanding the physiological and biochemical properties of PCPdegrading bacteria is required before optimum use of bacteria in environmental applications.

In order to find a strain able to degrade PCP in a changeable environment, we studied the effect of inoculum size and the influence of the $\mathrm{pH}$ of the medium on PCP degradation by a PCP-degrading bacterium, Pseudomonas sp., isolated from soils contaminated with PCP. 


\section{Experimental}

\section{Strain}

$P$. aeruginosa was isolated from a soil with a history of phenol contamination, wood chunks that had been exposed to formaldehyde and chlorophenol solutions, and a soil containing pentachlorophenol near a wastewater discharge site (Murialdo et al., 2003).

\section{Chemicals and reagents}

Pentachlorophenol (PCP 99\% pure) was obtained from Sigma Chemical Co. (St. Louis MO 63178 USA). All other chemicals used were of the highest purity commercially available.

\section{Culture conditions and media}

Minimal salts medium (MS) consisted of (in $\mathrm{g} \cdot \ell^{-1}$ ): $\mathrm{NaNO}_{3}$, 2.25; $\mathrm{K}_{2} \mathrm{HPO}_{4}, 2.83 ; \mathrm{KH}_{2} \mathrm{PO}_{4}, 0.507 ; \mathrm{Mg} \mathrm{SO}_{4} .7 \mathrm{H} 2 \mathrm{O}, 0.45$; $\mathrm{FeSO}_{4}, 0.135$ and $\mathrm{CaCl}_{2}, 0.45$. Where indicated, the $\mathrm{pH}$ of MS was adjusted to $\mathrm{pH}$ values of $5.5,6.3,7.1$ and 8 , changing the potassium-phosphate buffer system; $2 \mathrm{~g}$ glucose $\cdot \ell^{-1}$ were added to the MS and designated MSG when indicated. Pentachlorophenol was first converted to its sodium salt by dissolving it in $0.2 \mathrm{~N} \mathrm{NaOH}$ and then autoclaved. This stock solution of pentachlorophenate $\left(5000 \mathrm{mg} \cdot \ell^{-1}\right)$ was used to prepare the MS or MSG media supplemented with the different concentrations of PCP.

\section{Influence of $\mathrm{pH}$ of the medium on PCP degradation}

Pseudomonas sp. cells were grown in $50 \mathrm{~m} \ell$ MSG medium with $25 \mathrm{mg} \cdot \ell^{-1}$ of PCP at different $\mathrm{pH}$ values $(5.5,6.3,7.1$ and 8$)$. This mixture was contained in a $125 \mathrm{ml}$ Erlenmeyer flask. The cultures were placed on a shaker $\left(100 \mathrm{r} \cdot \mathrm{min}^{-1}\right)$ at $25^{\circ} \mathrm{C}$ in the dark, to avoid photodecomposition of PCP.

Growth was monitored by measuring the turbidity of the culture at $600 \mathrm{~nm}$, using a Shimadzu uV-160 spectrophotometer (Shimadzu Scientific Instruments INC., Columbia, MD, USA). Cells were harvested at $20 \mathrm{~h}$ during mid-log phase. Cultures (5 $\mathrm{m} \ell$ ) were centrifuged at $10000 \mathrm{r} \cdot \mathrm{min}^{-1}$ for $5 \mathrm{~min}$, the pellet was washed once with MS medium according to the different $\mathrm{pHs}$ used and resuspended in the same MS medium. This was used immediately as inoculum for the next batch. Pseudomonas sp. cells were inoculated into $50 \mathrm{~m} \ell$ of MS medium with $25 \mathrm{mg} \cdot \ell^{-1}$ of PCP, as the only source of carbon and energy, at different $\mathrm{pH}$ values. Cultures were maintained at $25^{\circ} \mathrm{C}$ on a shaker operated at $100 \mathrm{r} \cdot \mathrm{min}^{-1}$. Sample aliquots of $1 \mathrm{ml}$ were removed at $2 \mathrm{~h}$ intervals and the cells pelleted by centrifugation at $10000 \mathrm{r} \cdot \mathrm{min}^{-1}$ for 5 min. PCP degradation was assessed by measuring $\mathrm{A}_{320 \mathrm{~nm}}$ of the supernatant.

Controls included cells in MS without PCP added and MS medium supplemented with PCP without cells.

Viability was measured $2 \mathrm{~h}$ after the addition of the inoculum and when the degradation of PCP started. Serial dilutions of cells at each time were plated on MSG agar plus PCP $\left(25 \mathrm{mg} \cdot \ell^{-1}\right)$ and colony-forming units (CFU) enumerated following $48 \mathrm{~h}$ incubation at $30^{\circ} \mathrm{C}$.

\section{PCP degradation}

PCP degradation was established by measuring the PCP aromatic ring cleavage using a Shimadzu UV-160 spectrophotometer (Shimadzu Scientific Instruments INC., Columbia, MD,
USA) at $\mathrm{A}_{320}$ and compared with a standard curve. PCP $\mathrm{A}_{320}=1$ corresponding to $50 \mathrm{mg} \cdot \ell^{-1}$.

\section{Effect of inoculum size on PCP degradation}

The effect of inoculum size on PCP degradation was tested. Cells were grown as shake cultures at $25^{\circ} \mathrm{C}$ in $50 \mathrm{~m} \ell$ of MSG medium supplemented with $20 \mathrm{mg} \cdot \ell^{-1} \mathrm{PCP}$ at $\mathrm{pH} 7.1$ in $125 \mathrm{m \ell}$ Erlenmeyer flasks at $100 \mathrm{r} \cdot \mathrm{min}^{-1}$. Growth was monitored by measuring the turbidity of the culture at $\mathrm{A}_{600}$. During mid-log phase (at $20 \mathrm{~h}$ ) the viability was measured and different volumes of the MSG culture $(0.2 \mathrm{m \ell}, 1 \mathrm{m \ell}$ and $5 \mathrm{ml})$ were harvested by centrifugation at $10000 \mathrm{r} \cdot \mathrm{min}^{-1}$ for $5 \mathrm{~min}$. Thereafter, the pellets were washed once with MS medium and resuspended in the MS medium. The different inoculum sizes were transferred into 50 $\mathrm{m} \ell$ of MS medium supplemented with $20 \mathrm{mg} \cdot \ell^{-1}$ of PCP, as the only source of carbon and energy. At different times, PCP degradation was measured. The final concentration of the inoculum at the initial time in each treatment were: $1.8 \times 10^{6}, 9.04 \times 10^{6}$ and $4.5 \times 10^{7} \mathrm{CFU} / \mathrm{m} \ell$. These inoculum sizes were confirmed at the start of the experiment by plate count.

Controls included cells in MS without PCP and MS medium supplemented with PCP but without cells at $\mathrm{pH}$ 7.1.

The viability was measured at $24 \mathrm{~h}$ after addition of the inoculum and when the degradation started. Serial dilutions of cells were plated on MSG agar plus PCP $\left(25 \mathrm{mg} \cdot \ell^{-1}\right)$ and CFU enumerated following $48 \mathrm{~h}$ incubation at $30^{\circ} \mathrm{C}$.

\section{Specific rate of PCP degradation}

In order to establish how many $\mathrm{mg} \cdot \ell^{-1}$ of PCP had been degraded for each $\mathrm{CFU}$, the specific rate of PCP degradation was calculated as follows:

$$
\begin{aligned}
& \frac{(\partial \mathrm{PCP} / \partial \mathrm{t})}{\mathrm{CFU}} \\
& \text { where: } \\
& \text { PCP is the concentration of PCP in } \mathrm{mg} \cdot \ell^{-1} \\
& \text { CFU (colony-forming units per } \mathrm{m} \ell) \\
& \mathrm{t} \text { is the time in } \mathrm{h} \text {. }
\end{aligned}
$$

\section{Results}

\section{Influence of $\mathrm{pH}$ of the medium on PCP degradation}

Four $\mathrm{pH}$ values from 5.5 to 8 were investigated (Fig. 1). PCP was degraded rapidly at $\mathrm{pH} 6.3,7.1$ and 8 . At these $\mathrm{pH}$ values, PCP degradation was almost the same. However, the PCP degradation at $\mathrm{pH} 5.5$ was slower and the PCP concentration decreased rapidly after $80 \mathrm{~h}$ post-inoculation. In control cultures no aromatic ring cleavage occurred.

Pseudomonas sp. cells grew better at $\mathrm{pH}$ values within a range of 6 to 8 in MSG-medium than at $\mathrm{pH} 5.5$ (data not shown).

The specific consumption of PCP was analysed (Fig. 2). At $\mathrm{pH}$ values of 6.3 the specific rate of $\mathrm{PCP}$ degradation was greater than that obtained at $\mathrm{pH} 5.5,7.1$ or 8 . These results showed that each CFU of Pseudomonas sp. degraded more PCP per hour at $\mathrm{pH} 6.3$ than at any other $\mathrm{pH}$ value.

\section{Effect of inoculum size on PCP degradation}

PCP was degraded by Pseudomonas sp. during all the initial cell densities tested (Fig. 3). In cultures inoculated with 
the highest cell density $\left(4.5 \times 10^{7} \mathrm{CFU} \cdot \mathrm{m}^{-1}\right)$ the PCP concentration began to decrease rapidly after $20 \mathrm{~h}$ and reached $5 \mathrm{mg} \cdot \ell^{-1}$ after approximately $70 \mathrm{~h}$. Degradation was complete after $80 \mathrm{~h}$. However, in cultures receiving lower inoculum densities, there was a progressive decrease of PCP concentration. The PCP content began to decrease rapidly after $55 \mathrm{~h}$ and degradation was complete after $100 \mathrm{~h}$ with $9.04 \times 10^{6}$ and $1.8 \times 10^{6} \mathrm{CFU} \cdot \mathrm{m}^{-1}$. In control cultures no aromatic ring cleavage occurred.

In addition, the specific rate of PCP degradation was tested (Fig. 4). Cultures inoculated with $1.8 \times 10^{6} \mathrm{CFU} \cdot \mathrm{ml}^{-1}$ (lower inoculum size) showed the highest specific rate of PCP degradation, while the cultures inoculated with a higher inoculum size showed a decrease in specific consumption.

\section{Discussion}

Environmental factors such as $\mathrm{pH}$, temperature and other substrates in the environment may affect the growth of micro-organisms and their degradational abilities. In the present study Pseudomonas sp. could degrade PCP at a wide range of $\mathrm{pH}$, from 5.5 to 8 , with an optimum $\mathrm{pH}$ of 6.3 . Maximum degradation of all population and maximum specific consumption was at $\mathrm{pH}$ 6.3. It is possible that the enzymes for PCP degradation have their optimum enzymatic activity at $\mathrm{pH} 6.3$. At $\mathrm{pH}$ values either higher or lower than 6.3 , the rate of degradation was low.

The range of $\mathrm{pH}$ at which other strains degrade PCP was considerably narrower than the strain analysed in this work. Premalatha and Rajakumar (1994) reported a strain of Pseudomonas aerugi-

\section{Right, from top to bottom:}

Figure 1

$P C P$ biodegradation by Pseudomonas $s p$. cells at different $p H$ values. The initial PCP concentration was $25 \mathrm{mg} \cdot \ell^{-1}$. PCP degradation was assessed by measuring the cleavage of the aromatic ring at $A_{320 \mathrm{~nm}}\left(P C P A_{320}=1\right.$ correspond to $\left.50 \mathrm{mg} \cdot \mathrm{\ell}^{-1}\right)$. Results are means $\pm S D(n=4)$.

Figure 2

Influence of $\mathrm{pH}$ of the medium on the specific rate of $P C P$ degradation. The specific rate of $P C P$ degradation is expressed as $P C P \mathrm{mg} \cdot h^{-1}$. CFU ${ }^{-1}$. Results are means $\pm S D(n=4)$.

Figure 3

Effect of inoculum size on PCP degradation. Three different amount of inoculum were tested. The inoculum size is expressed as CFU.m $\mathrm{l}^{-1}$ in the final medium. The initial PCP concentration was 20 $\mathrm{mg} \cdot \ell^{-1} . M S$ medium without cells was used as a control. Results are means $\pm S D(n=3)$.

\section{Figure 4}

Relation between the specific rate of PCP degradation by Pseudomonas $s p$. and inoculum size. The inoculum size is expressed as CFU.m $\ell^{-1}$ in the final medium. The specific rate of $P C P$ degradation is expressed as PCP $m g \cdot h^{-1} \cdot C F U^{-1}$. Results are means $\pm S D(n=3)$.
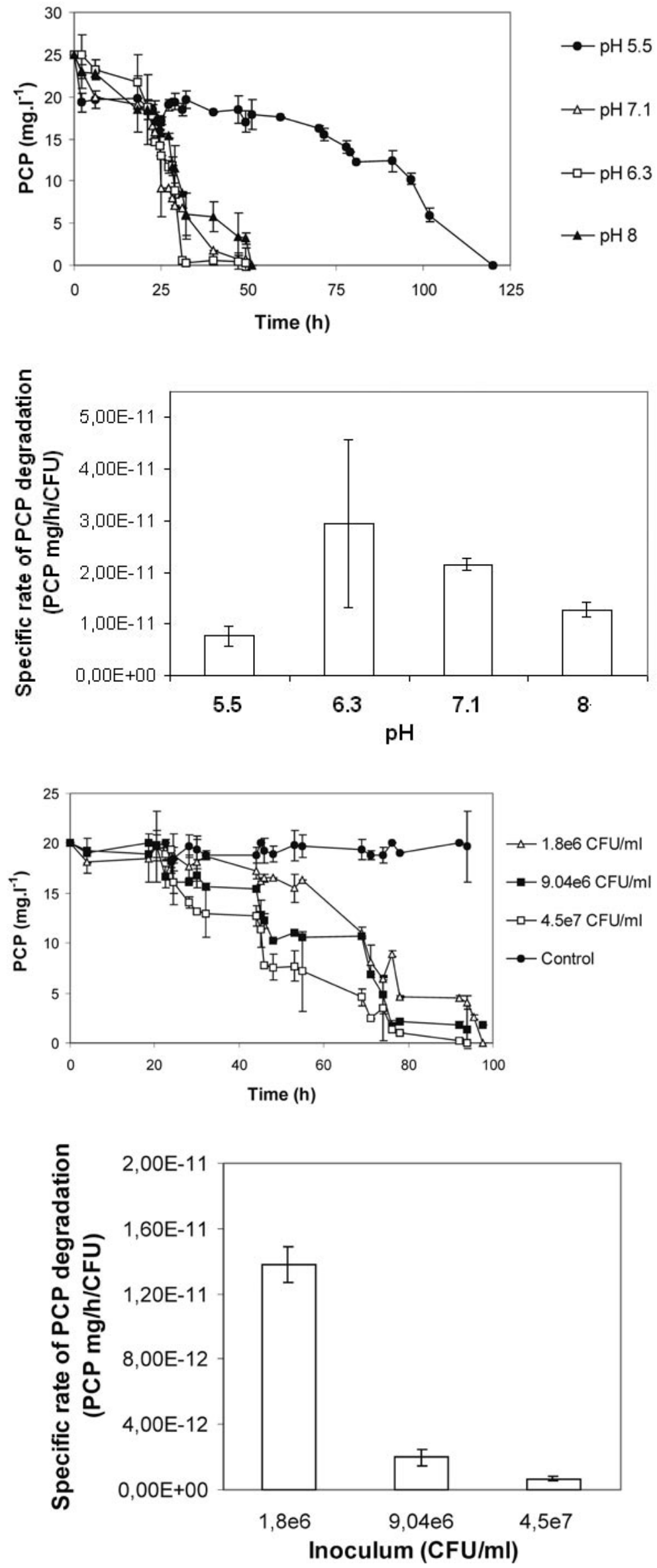
nosa that degraded PCP at $\mathrm{pH}$ of between 7 and 8. Degradation decreased slowly above $\mathrm{pH} 8$, and below $\mathrm{pH} 7$ PCP was toxic to Pseudomonas aeruginosa. In addition, PCP degradation by Flavobacterium sp. (González and Hu, 1991) decreased considerably below $\mathrm{pH}$ 6.9. The acidification of natural environments may enhance the toxicity of PCP (Rutgers et al., 1998). Therefore, it is very important to find strains that degrade PCP at low $\mathrm{pH}$. The strain of Pseudomonas studied in this work was able to degrade the PCP of the medium completely at $\mathrm{pH}$ 5.5, after a lag time. In addition, the lag phase of batch cultures was found to depend on PCP concentration and prior adaptation of the inoculum (unpublished data).

Interaction between micro-organisms responsible for degradation and transport of phenols/chlorophenols in the environment has been difficult to understand. This interaction is relevant, not only because it occurs before the metabolic reaction, but also because it is involved in the movement of phenol and chlorophenol in the environment. Some reports describe the biosorptive uptake of PCP on suspended biomass as being primarily influenced by $\mathrm{pH}$. Brandt et al. (1997) corroborated the $\mathrm{pH}$ effect on the biosorptive uptake of PCP by Mycobacterium chlorophenolicum PCP-1. Antizar-Ladislao and Galil (2004) reported that an increase in $\mathrm{pH}$ value decreased the equilibrium sorption. This observation may be because as the $\mathrm{pH}$ increased, the overall surface charge on the cells became negative and this led to a lower electrostatic attraction between negatively charged phenol/chlorophenol and binding sites of the biomass surface. Daughney and Fein (1998) showed that an increase in $\mathrm{pH}$ from 5 to 9 showed a decrease in the percentage of 2, 4, 6 -TCP sorbed by Bacillus subtilis. It is known that there is some relationship between biosorption and biodegradation. Our results are in agreement with reports mentioned above and are correlated with the fact that there would be an increase in biosorption and in the specific rate of PCP degradation at $\mathrm{pH} 6.3$ in Pseudomonas sp.

On the other hand, Pseudomonas sp. cells grew better at $\mathrm{pH}$ values within a range of 6 to 8 in MSG-medium than at $\mathrm{pH} 5.5$ (data not shown). The same behaviour was described by Tsuji et al. (1982). The dependence of $\mathrm{pH}$ on growth rate may be explained as described by Tyler and Finn (1974) and Rutgers et al. (1998); at a given $\mathrm{pH}$ there is a certain amount of substrate present in dissociated and undissociated form. The undissociated form is the species that is believed to penetrate the cell membrane and to be responsible for both metabolic and inhibitory activity. Antizar-Ladislao and Galil (2004) reported that the $\mathrm{pH}$ primarily affects the degree of ionisation of phenol/chlorophenol and the surface properties of the biomass. At the $\mathrm{pH}$ range 6 to 9 the overall surface charge of the biomass was negative and this led to a lower electrostatic attraction between negatively charged PCP and binding sites of the biomass surface. These authors report a $\mathrm{p} K_{\mathrm{a}}$ value of 6.59 for PCP. This could explain the lower growth rate of Pseudomonas sp. at pH 5.5 than at higher pHs in our work.

PCP degradation by Pseudomonas sp. increases linearly with the increase of inoculum size (Fig. 3), such as described by Shaw et al. (1997) for a PCP mineralising Pseudomonas sp. UG 30 and by Bidlan and Manonmani (2002) for a strain of Serratia marcescens DT-1P that degrades dichlorophenyltrichloroethane.

An effective bacterial inoculum able to tolerate and degrade high levels of PCP was $4.5 \times 10^{7} \mathrm{CFU} \cdot \mathrm{m}^{-1}$. However, our results show that an increase in the amount of inoculum did not improve the specific rate of PCP degradation. More research is needed to prove the possible existence of self-regulation in the Pseudomonas sp. population.

\section{Conclusions}

Our study showed that changes in the $\mathrm{pH}$ values of the culture mediums, and changes in the inoculum size affected the specific rate of PCP degradation by Pseudomonas sp. A pH value of 6.3 and an inoculum size of $4.5 \times 10^{7} \mathrm{CFU} \cdot \mathrm{m}^{-1}{ }^{-1}$ were the optimal conditions to obtain the maximal degradation of PCP in this batch experimental system.

The strain studied in the work reported here was able to degrade $\mathrm{PCP}$ over a wide range of $\mathrm{pHs}$, particularly at $\mathrm{pH}$ as low as 5.5. This is an important characteristic for the bioremediation of changeable environments.

Another feature worth mentioning is that this particular strain had shown that it was capable of degrading phenol, lower substituted chlorophenols and hexadecane (Murialdo et al., 2003). This final compound is very important because it is cosubstrate of PCP and produces an increase of biomass.

The information provided here can be used to optimise degradation conditions in the field, by adjusting the $\mathrm{pH}$ to provide the inoculum with a competitive advantage over the natural flora. The inoculum size is another tool to achieve a good rate of PCP degradation, since usually, when remediating contaminated soils, the cost of growing the inoculum is lower than the cost of soil movement.

Preliminary identification of this strain has been carried out and further work continues on their characterisation. However, more research is necessary to understand the mechanisms of microbial degradation and to improve the conditions for in situ bioremediation of PCP-contaminated soils.

\section{Acknowledgments}

This research was supported by ANPCYT, Argentina (Grant 1303246), and the Universidad Nacional de Mar del Plata. EA Wolski would like to thank ANPCYT, Argentina for the fellowship granted to her and C Rodriguez and M Lanfranconi for their kind co-operation.

\section{References}

ANTIZAR-LADISLAO B and GALIL NI (2004) Biosorption of phenol and chlorophenols by acclimated residential biomass under bioremediation conditions in a sandy aquifer. Water Res. 38 267-276.

APAJALAHTI JHA and SALKINOJA-SALONEN MS (1986) Degradation of polychlorinated phenols by Rhodococcus chlorophenolicus. Appl. Microbiol. Biotechnol. 25 62-67.

BIDLAN R and MANONMANI HK (2002) Aerobic degradation of dichlorodiphenyltrichloroethane (DDT) by Serratia marcescens DT-1P. Proc. Biochem. 38 49-56.

BRANDT S, ZENG A and DECKWER W (1997) Adsorption and desorption of PCP on cells of Mycobacterium chlorophenolicum PCP-1. Biotechnol. Bioeng. 55 480-491.

BORTHWICK PW and SCHIMMEL SC (1978) Toxicity of pentachlorophenol and related compounds to early life stages of selected estuarine animals. In: K. Ranga Rao (ed.) Pentachlorophenol: Chemistry, Pharmacology and Environmental Toxicology. Plenum Press, New York.

CHU JP and KIRSCH EJ (1972) Metabolism of pentachlorophenol by an axenic bacterial culture. Appl. Microbiol. 23 1033-1035.

CHU JP and KIRCH EJ (1973) Utilization of halophenols by a pentachlorophenol metabolizing bacterium. Dev. Ind. Microbiol. 14 264-273.

CIRELLI DP (1978) Patterns of pentachlorophenol usage in The United States of America: An overview. In: Rao KR (ed.) Pentachlorophenol. Plenum Press, New York, USA.

DAUGHNEY CJ and FEIN JB (1998) Sorption of 2, 4, 6-TCP by Bacillus subtilis. Environ. Sci. Technol. 32 749-752. 
GONZÁLEZ JF and HU WS (1991) Effect of glutamate on the biodegradation of pentachlorophenol. Appl. Microbiol. Biotechnol. 35 100104.

HOOS RAW (1978) Patterns of pentachlorophenol usage in Canada: An overview. In: Rao KR (ed.) Pentachlorophenol. Plenum Press, New York, USA.

LIU D, THOMASON K and KAISER KLE (1982) Quantitative structure toxicity relationship of halogenated phenols in bacteria. Bull. Environ. Contam. Toxicol. 29 130-139.

Mc ALLISTER KA, LEE H and TREVORS JT (1996) Microbial degradation of pentachlorophenol. Biodegradation 7 1-10.

MURIALDO SE, FENOGLIO R, HAURE PM. and GONZALEZ JF (2003) Degradation of phenol and chlorophenols by mixed and pure cultures. Water SA 29 457-463.

PREMALATHA A and RAJAKUMAR GS (1994) Pentachlorophenol degradation by Pseudomonas aeruginosa. World J. Microbiol. Biotechnol. 10 334-337.

RADEHAUS RM and SCHMIDT SK (1992) Characterization of a novel Pseudomonas sp. that mineralizes high concentrations of pentachlorophenol. Appl. Environ. Microbiol. 58 2879-2885.

RAO KR (1978) Chemistry, pharmacology and environmental toxicology. In: Rao KR (ed.) Pentachlorophenol. Plenum Press, New York, USA.
RUTGERS M, VAN BOMMEL S, BREURE AM, VAN ANDEL JG and DUETZ WA (1998) Environmental toxicology and effect of $\mathrm{pH}$ on the toxicity and biodegradation of PCP by Sphingomonas sp. strain P5 in nutristat culture. Chem. 17 792-797.

SABER DL and CRAWFORD RL (1985) Isolation and characterization of Flavobacterium strains that degrade pentachlorophenol. Appl. Environ. Microbiol. 50 1512-1518.

SHAW KW, LEE H and TREVORS J (1997) Effect of initial cell density, substrate concentration and temperature on pentachlorophenol degradation by Pseudomonas sp. UG-30. J. Chem. Technol. Biotechnol. 69 107-113.

STANLAKE GJ and FINN RK (1982) Isolation and characterization of a pentachlorophenol-degrading bacterium. Appl. Environ. Microbiol. 44 1412-1427.

TYLER JE and FINN RK (1974) Growth rates of a Pseudomonas on 2, 4-D and 2, 4-DCP. Appl. Microbiol. 28 181-184.

TSUJI A, KANEKO Y, TAKAHASHI K, OGAWA M and GOTO S (1982) The effect of temperature and $\mathrm{pH}$ on the growth of eight enteric and nine glucose non-fermenting species of gram-negative rods. Microbiol. Immunol. 26 15-24.

VALO R, KITUNEN V, SALKINOJA-SALONEN MS and RAISONEN S (1985) Chlorinated phenols and their derivatives in soil and ground water around wood-preserving facilities in Finland. Water Sci. Technol. 17 1381-1384. 
Available on website http://www.wrc.org.za ISSN 0378-4738 = Water SA Vol. 32 No. 1 January 2006 ISSN 1816-7950 = Water SA (on-line) 